\title{
Spatial packing of diols and esters with imidazoquinazoline ring-quantum-mechanical modeling
}

\author{
K. Hęclik ${ }^{1} \cdot$ A. Szyszkowska ${ }^{2}$ • I. Zarzyka ${ }^{2}$ (D)
}

Received: 4 January 2019 / Accepted: 25 February 2019 / Published online: 18 March 2019

(C) The Author(s) 2019

\begin{abstract}
This work explains the spatial arrangement of two derivatives of 1-phenyl-2H,6H-imidazo[1,5-c]quinazoline-3,5-dione (PIQ), i.e., diester 2,6-bis(ethoxycarbonylmethyl)-1-phenylimidazo[1,5-c]quinazoline-3,5-dione (BEPIQ) and 2,6-bis(2-hydroxyethyl)-1phenylimidazo[1,5-c]quinazoline-3,5-dione (BHEPIQ). Studies of a single crystal by X-ray crystallography showed a different way of arranging the diol and diester molecules in the crystals. Quantum-mechanical modeling showed the overlapping of the highest occupied molecular orbitals (HOMO) and lowest unoccupied molecular orbitals (LUMO) of BEPIQ enantiomeric molecules in relation to each other in the "head to tail" position. The formation of charge-transfer complexes stabilizes the system and is responsible for the packing density of the BEPIQ molecules in the crystal. The BEPIQ enantiomeric pairs are positioned at an angle of $67^{\circ}$ to each other forming the herringbone in the crystal lattice. In addition, the BEPIQ crystal has the ability to form inclusion compounds. Based on the calculations, it was found that the overlapping of molecular orbitals of BHEPIQ molecules is not possible. It results from a different distribution of electron density in imidazoquinazoline ring as compared to the molecule of the BEPIQ. The formation of intermolecular hydrogen bonds is responsible for the spatial arrangement of the BHEPIQ molecules. The BHEPIQ molecules are arranged in a "head to head" position, and in the crystal, they form stackings.
\end{abstract}

Keywords Imidazoquinazolinedione - Spatial structure - Quantum-mechanical modeling · Charge-transfer complexes · Molecular orbital $\cdot$ Inclusion compounds

\section{Introduction}

There are interactions between molecules in the crystal that keep them close to each other. Intermolecular interactions can be divided into long-range (attractive forces) and short-range interactions (repulsive forces). The result of these interactions leads to a state of equilibrium. The attractive interactions include van der Waals interactions and interactions related to the transfer of charge, i.e., hydrogen bonds, $\pi-\pi$ interactions, or charge-transfer complexes.

\section{Zarzyka}

izarzyka@prz.edu.pl

1 Department of Biochemistry and Biotechnology, Faculty of Chemistry, Rzeszow University of Technology, Powstańców Warszawy 6, 35-959 Rzeszów, Poland

2 Department of Organic Chemistry, Faculty of Chemistry, Rzeszow University of Technology, Powstańców Warszawy 6 , 35-959 Rzeszów, Poland
The van der Waals interactions are weak interactions between the molecules. They are the sum of forces: dispersive, electrostatic, inductive, and repulsive. The attractive forces keep the atoms close to each other. In turn, the repulsive forces are the result of the repulsion of nuclei and non-valence electrons. For each atom, it is possible to indicate the so-called van der Waals radius in determining the distance that two solidstate atoms can approach without interactions between their valence electrons [1-3].

Molecules with an even distribution of electric charge can attract each other by close contact of electrons in the external sphere of atoms and the formation of temporary asymmetries in charge distribution. These interactions are called dispersive. Between molecules with stable dipole moments, attractive electrostatic interactions of the dipole-dipole type can also be created, in which a positive dipole charge of one molecule approaches the negative dipole charge of another molecule. The dipole moment can also be induced in a molecule which is close to the polar molecule. These are called induced interactions [4].

A hydrogen bond is an interaction in which a hydrogen atom is attracted by two highly electronegative atoms between 

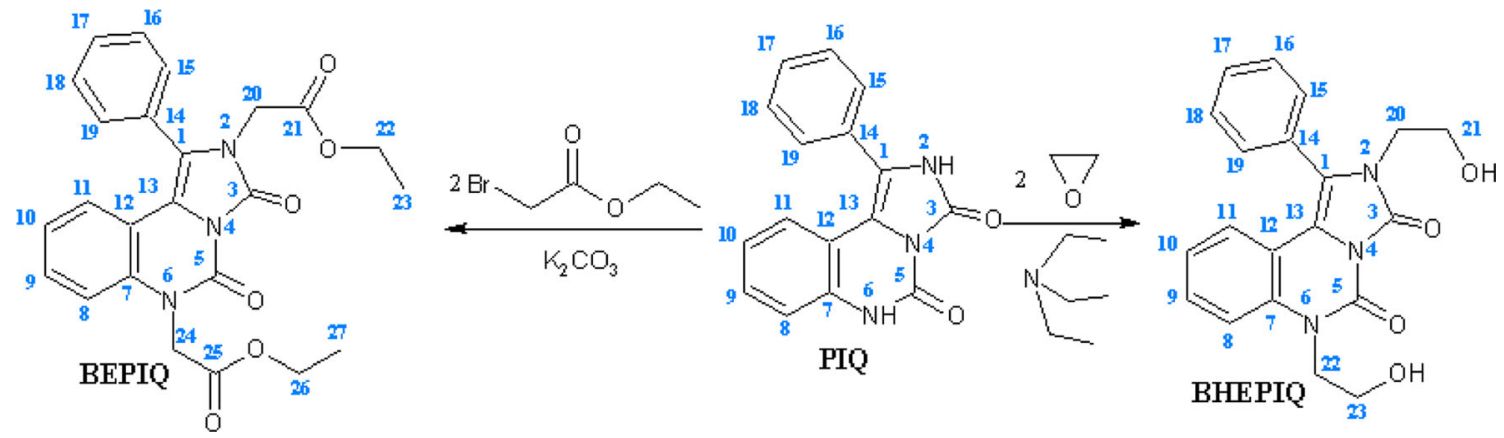

Fig. 1 Reaction scheme of PIQ with two-molar excess ethyl bromoacetate and ethylene oxide

which it is located. The hydrogen electron moves towards the atom with which the hydrogen does not form a covalent bond. A specific bridge is created between the electron donor and acceptor. Hydrogen interactions are directional and anisotropic. Strong hydrogen bonds include $\mathrm{OH} \bullet \bullet \mathrm{O}, \mathrm{NH} \bullet \bullet \mathrm{O}, \mathrm{NH} \bullet \bullet \mathrm{N}$ contact with distances between the acceptor and donor in the range of 2.4-2.8 $\AA$. Weak hydrogen bonds are mainly electrostatic interactions. In turn, strong hydrogen bonds are also characterized by quite important contributions from dispersion interactions. The strongest hydrogen bonds have a linear structure. In many crystalline structures, there are very weak $\mathrm{C}-\mathrm{H} \cdots \mathrm{O}$ and $\mathrm{C}-\mathrm{H} \cdots \mathrm{N}$ interactions as well as interactions with the $\mathrm{C}-\mathrm{H} \cdots \cdots \pi$ and $\mathrm{N}-\mathrm{H} \cdots * \pi$ electron cloud that affect the packing geometry [5-7].

Interactions of $\pi-\pi$ occur when two aromatic rings form planes that are parallel to each other. The distance between the planes of the rings is usually $3.3-3.6 \AA$. The dispersive interactions have the largest share in the interactions of $\pi-\pi$. Electrostatic interactions are the factors determining the geometry of the complex [8-11].

The charge-transfer interactions are another interaction type in this type of complexes. They appear when the electron-acceptor groups are substituted at the aromatic ring.
Complexes with charge transfer are molecular adducts or aggregates generated by the connection between the electron donor and the electron acceptor, where the association results from non-covalent interactions $[12,13]$.

Charge-transfer complexes involve two molecules that exhibit weak relative attraction, which is stronger than van der Waals forces and weaker than a hydrogen bond. In such a system, the charge is transferred from one molecule to the other. It results in the formation of a very weak binding molecular orbital, in which a small proportion of the acceptor orbital is included in the wave function of the donor's orbital.

Due to the mentioned interactions, aromatic rings (homoand heterocyclic) tend to aggregate. The flat arrangement of the rings is often conducive to high-density packing of molecules in the crystal.

The most common ways of packing aromatic molecules in a crystal are stackings and herringbone. Stackings are the arrangement of flat or almost flat particles in the columns, one above the other. In this arrangement, the aromatic rings are spaced only by $3.3-3.6 \AA$. Two molecules arranged in parallel with the rings may be aligned with each other "head to head" if groups attached to the rings lie directly above each other or "head to tail" when attached groups lie on opposite sides.

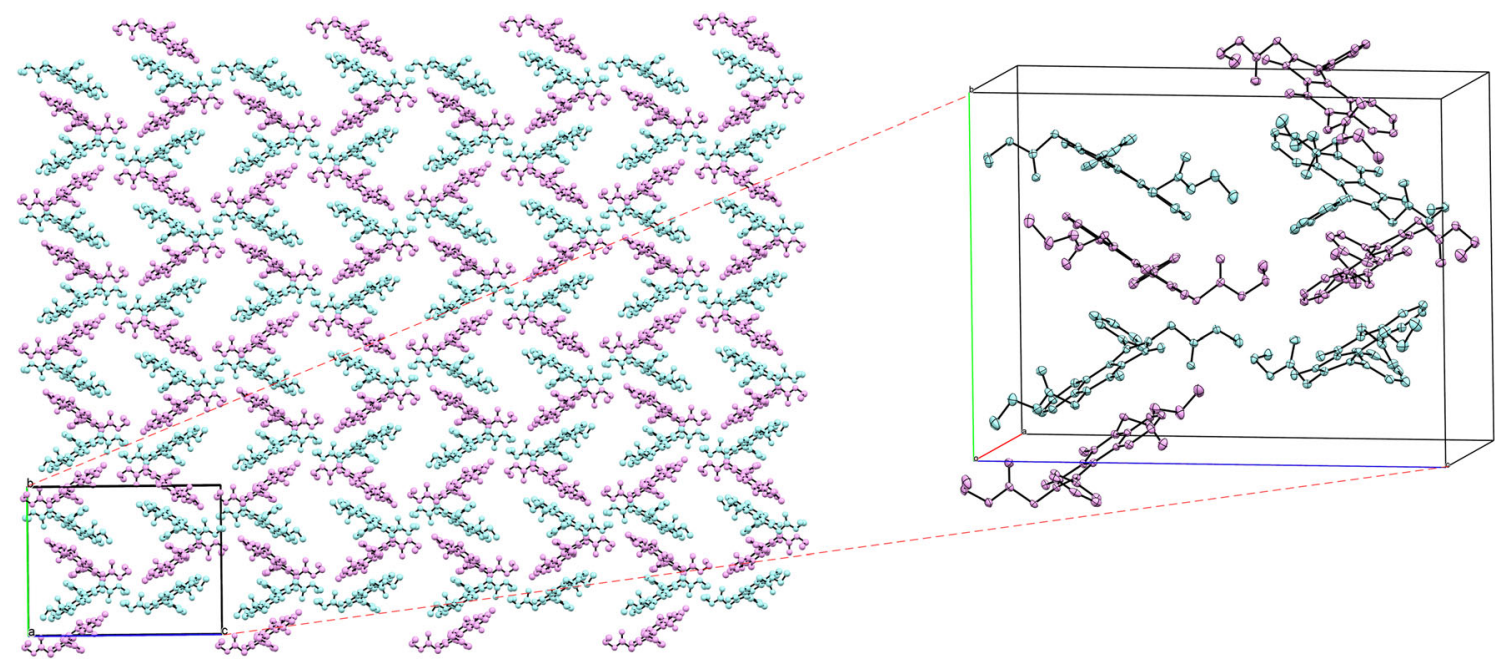

Fig. 2 The BEPIQ crystal lattice with the details of the unit cell. The figure does not show all molecules building the crystal but only the BEPIQ molecules, the benzene (solvent) molecules are omitted 


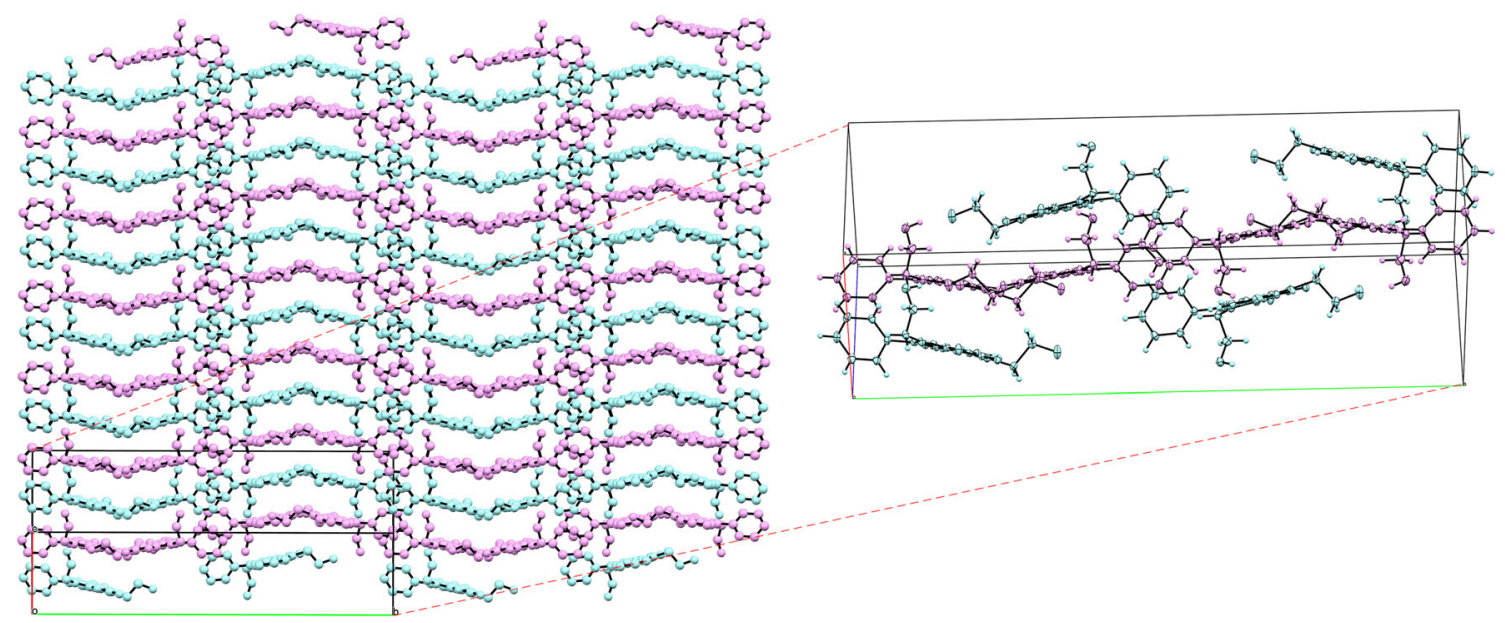

Fig. 3 The BHEPIQ crystal lattice with the details of the unit cell

A herringbone arrangement means packing in which the planes of neighboring molecules are inclined with respect to each other, usually by an angle of $70-90^{\circ}$. In both types of structures, characteristic interactions appear [14-20].

Charge-transfer complexes are very popular among researchers due to their wide application in many fields, including as organic semiconductors [21], organic solar cells [22], and substances used in photocatalysis [23], and due to their electrical properties $[24,25]$.

For several decades, the subject of interest in organic physic-chemistry is the design of electronic organic materials based on complexes with charge transfer [12, 13, 26-29].

Recently, complexes with charge transfer are of great importance in the field of drug receptor research and DNA chain binding as well as antibacterial and antimicrobial tests [30].

The aim of the work is to explain, on the basis of quantummechanical calculations, a different spatial arrangement of 1phenyl-2H,6H-imidazo[1,5-c]quinazoline-3,5-dione (PIQ) derivatives: diester-2,6-bis(ethoxycarbonylmethyl)-1phenylimidazo[1,5-c]quinazoline-3,5-dione (BEPIQ) and diol-2,6-bis(2-hydroxyethyl)-1-phenylimidazo[1,5-c]quinazoline-3,5-dione (BHEPIQ) with respect to each other in the crystal.

Theoretical calculations were carried out using the DFT methods using the B3LYP functional and the $6-311++\mathrm{G}(\mathrm{d}, \mathrm{p})$ basis set. Quantum-mechanical modeling was aimed at optimizing the structure of the considered derivatives, calculating geometrical parameters, electrostatic molecular potential, and atomic charges by the natural bond orbital (NBO) method. In addition, the distribution of electron density of individual molecules and forming complexes with charge transfer was calculated (HOMO and LUMO).

The main aim of the article is to show that the crystal structure of the tested PIQ derivatives is related with the formation of complexes with charge transfer by molecule's BEPIQ enantiomers and the hydrogen bond's presence in the case of the BHEPIQ molecules.

\section{Methodology}

The computational studies of the BEPIQ and BHEPIQ molecules were carried out using the Gaussian 09 application [31]. This tool was used to calculate bond lengths, bond angles, dihedral angles, atomic charges, maps of molecular electrostatic potentials, and surface characteristics of the highest occupied molecular orbitals (HOMO) and the lowest unoccupied molecular orbitals (LUMO) of the complex with charge transfer of the BEPIQ molecules. Furthermore, the bond-length alternation (BLA) parameter
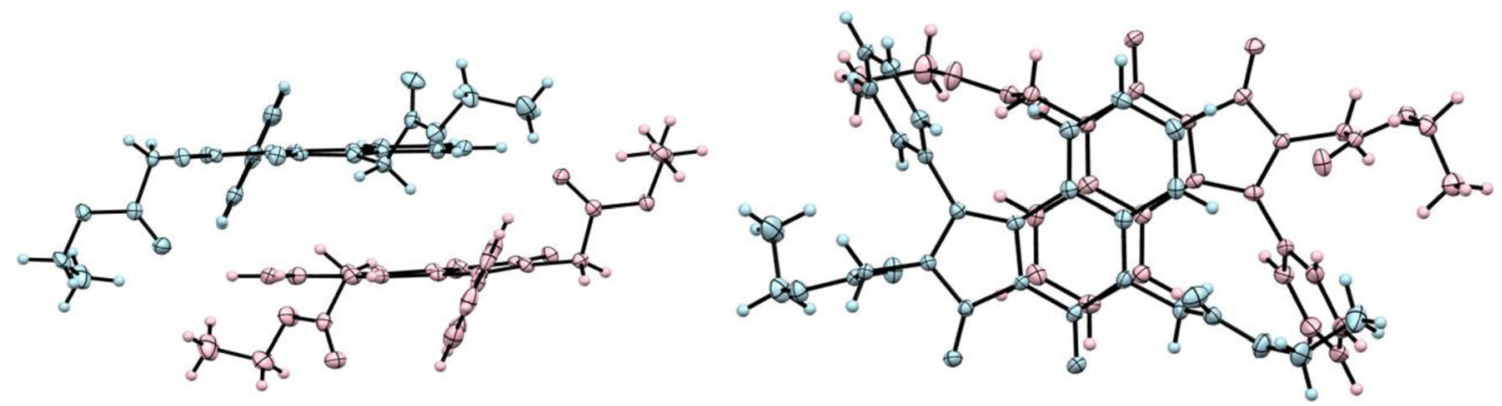

Fig. 4 An arrangement of the BEPIQ enantiomers with respect to each other in the crystals 

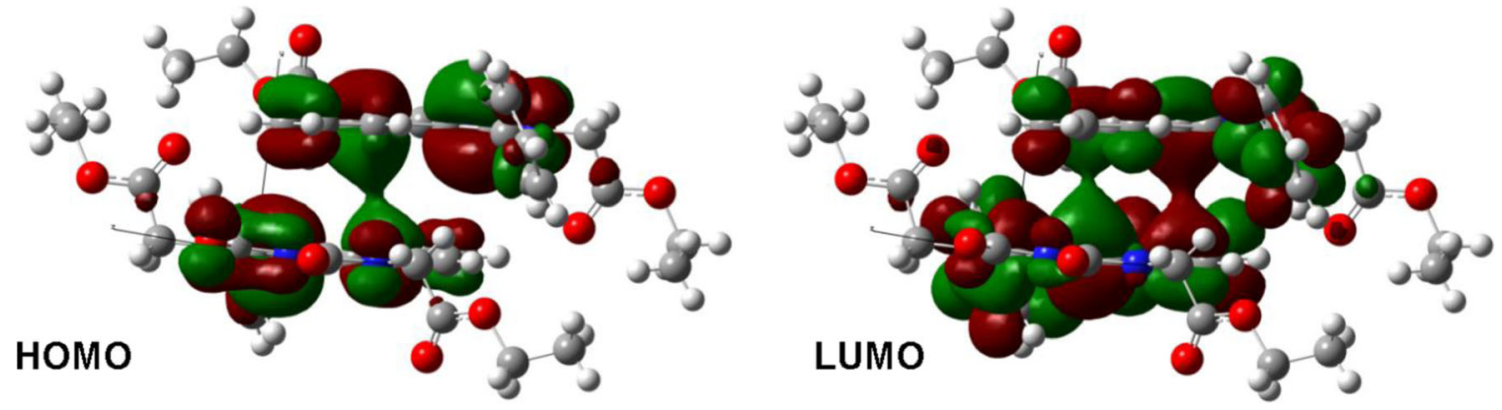

Fig. 5 The HOMO and LUMO of the BEPIQ enantiomers that make up the crystal

was calculated. The optimization of dimer structure taking into account the effect of environment polarization was made with model IEFPCM which couples both the PCM and COSMO models. The optimization calculations and the single-point calculations were made using the DFT methods [32], using the B3LYP functional and the 6$311++\mathrm{G}(\mathrm{d}, \mathrm{p})$ basis set [33], taking into account the Grimme correction for dispersion interactions. The modeling of potential energy surface was made using the 6$311++G(d, p)$ basis set $[34,35]$. Structure visualization was performed using GaussView [36] and Mercury [37], while the Hirshfeld surface-CrystalExplorer [38].

\section{Discussion of results}

During the reaction of PIQ with a two-molar excess of ethyl bromoacetate or ethylene oxide, 2,6bis(ethoxycarbonylmethyl)-1-phenylimidazo[1,5-c]quinazoline-3,5-dione (BEPIQ) and 2,6-bis(2-hydroxyethyl)1-phenylimidazo[1,5-c] quinazoline-3,5-dione (BHEPIQ) are formed, respectively. It is shown in Fig. 1.

The structure of the analyzed derivatives has been confirmed by the instrumental methods, including single-crystal studies using a structural X-ray analysis, in what was described in detail in [39, 40].

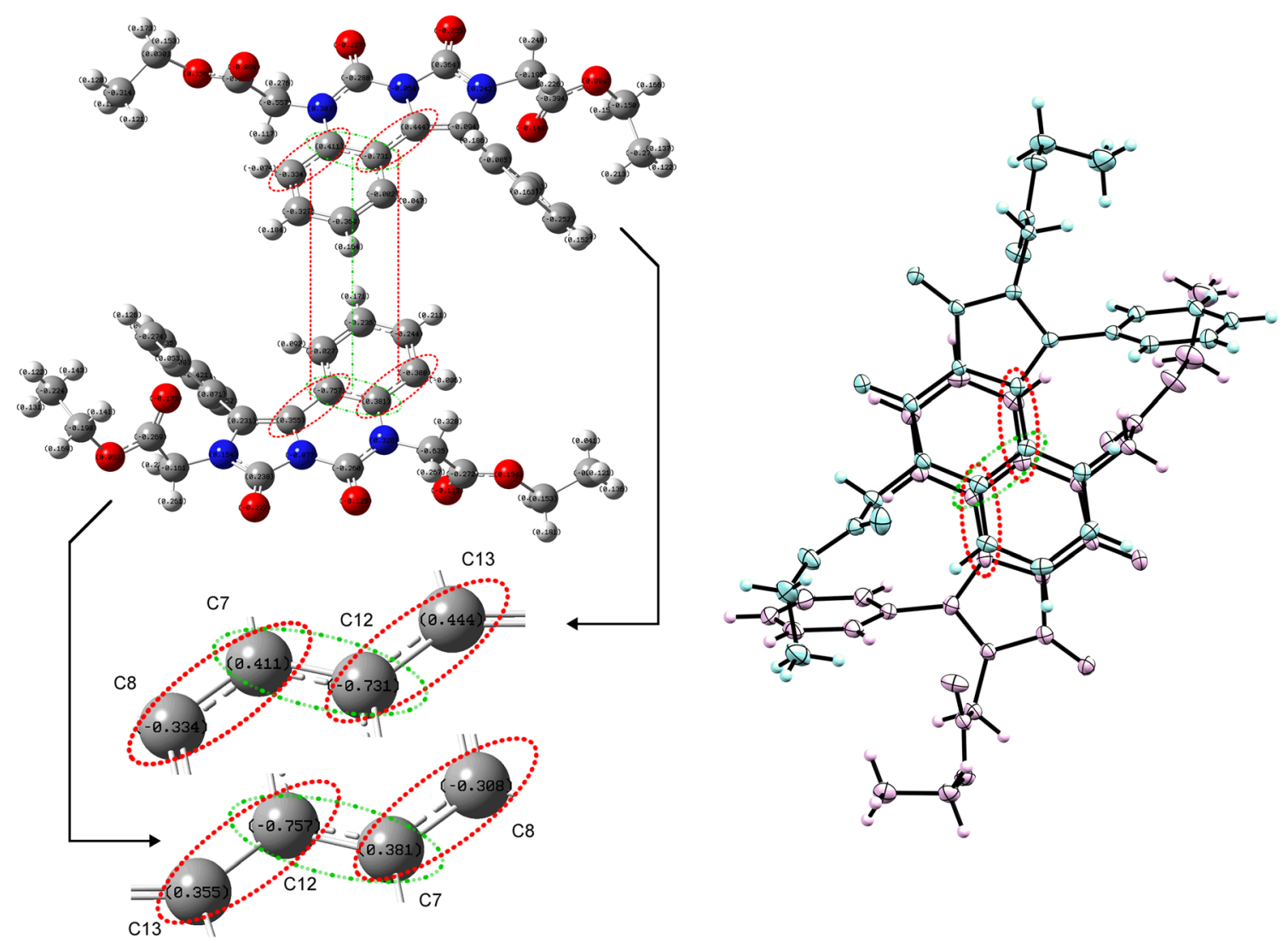

Fig. 6 Scheme of overlapping of the BEPIQ enantiomeric molecules. Atoms were provided with the values of load point charges 

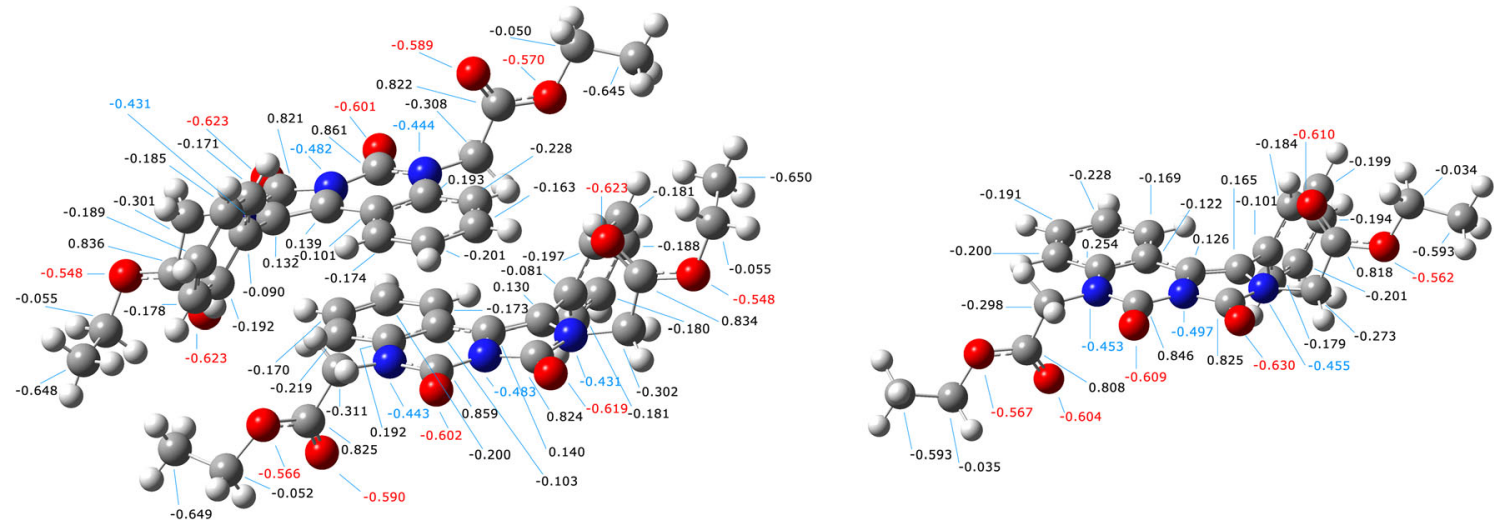

Fig. 7 Point charges of BEPIQ calculated for a pair of enantiomeric molecules and for a single molecule. Point charges of hydrogen atoms were omitted for clarity

Crystallographic studies revealed a different way of arranging the molecules of BEPIQ and BHEPIQ with respect to each other in the crystals. The spatial structure of BEPIQ and BHEPIQ is shown in Figs. 2 and 3, respectively.

A thorough analysis of the BEPIQ unit cell showed there are two slightly different molecules present. They are represented on pictures by blue and pink colors in Fig. 2. The blue and pink molecules forming the pair are shown in Fig. 4. They are related to each other by pseudo-inversion center because the dimer is not exactly centrosymmetric. In the P212121 space group describing the symmetry of the crystal, the center of symmetry is not present. They differ slightly, mainly by a torsion angle change of carboxylic groups. Therefore, a pair of enantiomers can be observed in the non-centrosymmetric space group.

The ester substituents assume a position parallel to the plane of the imidazoquinazoline ring. The quinazoline rings are arranged exactly one above the other, but rotated by $180^{\circ}$ in the plane, i.e., the molecules are in the "head to tail" position, as shown in Fig. 4.

The distance between the planes of the imidazoquinazoline rings is $3.5 \AA$. This arrangement of the BEPIQ enantiomeric molecules suggests the interaction of $\pi-\pi$ between the aromatic rings [8].

In order to find the causes of the placement of the BEPIQ enantiomeric molecules, quantum-mechanical modeling was performed. Calculations made in the single point for the BEPIQ enantiomeric pair revealed the overlapping of HOMO and LUMO. The HOMO and LUMO shapes of the BEPIQ enantiomeric pair are shown in Fig. 5.

Electron transfer between the imidazoquinazoline rings of individual BEPIQ enantiomeric pairs is made possible by the difference in charge distribution in the quinazoline rings. The point charges of the BEPIQ enantiomeric molecules are shown in Figs. 6 and 7. The dimer of the BEPIQ enantiomers is not exactly centrosymmetric. Therefore, the values of point

Table 1 Single molecule vs. dimer BLA parameters

\begin{tabular}{|c|c|c|c|c|c|c|}
\hline Bond & Length $(\AA)$ in $\mathrm{GE}^{\prime}$ (single) & Length $(\AA)$ in $\mathrm{GE}^{\prime}$ (dimer) & $\Delta(\AA)$ & Length $(\AA)$ in $\mathrm{HF}^{\prime}$ (single) & Length $(\AA)$ in $\mathrm{HF}^{\prime}$ (dimer) & $\Delta(\AA)$ \\
\hline $\mathrm{N}_{2}-\mathrm{C}_{1}$ & 1.40274 & 1.39951 & 0.00323 & 1.40274 & 1.40863 & -0.00589 \\
\hline $\mathrm{C}_{1}-\mathrm{C}_{13}$ & 1.35770 & 1.35672 & 0.00098 & 1.35768 & 1.36215 & -0.00447 \\
\hline $\mathrm{C}_{13}-\mathrm{C}_{12}$ & 1.44506 & 1.44483 & 0.00023 & 1.44508 & 1.44770 & -0.00262 \\
\hline $\mathrm{C}_{12}-\mathrm{C}_{7}$ & 1.41245 & 1.40879 & 0.00366 & 1.41248 & 1.40619 & 0.00629 \\
\hline $\mathrm{C}_{7}-\mathrm{C}_{6}$ & 1.41308 & 1.42002 & -0.00694 & 1.41306 & 1.41884 & -0.00578 \\
\hline $\mathrm{C}_{7}-\mathrm{C}_{8}$ & 1.40083 & 1.40047 & 0.00036 & 1.40083 & 1.39780 & 0.00303 \\
\hline $\mathrm{C}_{8}-\mathrm{C}_{9}$ & 1.39046 & 1.38298 & 0.00748 & 1.39045 & 1.38267 & 0.00778 \\
\hline $\mathrm{C}_{9}-\mathrm{C}_{10}$ & 1.39327 & 1.38567 & 0.00760 & 1.39328 & 1.38983 & 0.00345 \\
\hline $\mathrm{C}_{10}-\mathrm{C}_{11}$ & 1.38744 & 1.38316 & 0.00428 & 1.38743 & 1.38497 & 0.00246 \\
\hline $\mathrm{C}_{11}-\mathrm{C}_{12}$ & 1.40240 & 1.39906 & 0.00334 & 1.40239 & 1.39744 & 0.00495 \\
\hline BLA* & -0.02255 & -0.02535 & 0.00280 & -0.02255 & -0.02605 & 0.00349 \\
\hline $\mathrm{BLA}^{* *}$ & -0.35220 & -0.03870 & 0.00348 & -0.03521 & -0.04089 & 0.00567 \\
\hline
\end{tabular}

$* \mathrm{BLA}=\left(R_{\mathrm{C} 1-\mathrm{C} 13}+R_{\mathrm{C} 12-\mathrm{C} 7}+R_{\mathrm{C} 8-\mathrm{C} 9}+R_{\mathrm{C} 10-\mathrm{C} 11}\right) / 4-\left(R_{\mathrm{N} 2-\mathrm{C} 1}+R_{\mathrm{C} 13-\mathrm{C} 12}+R_{\mathrm{C} 7-\mathrm{N} 6}+R_{\mathrm{C} 7-\mathrm{C} 8}+R_{\mathrm{C} 9-\mathrm{C} 10}+R_{\mathrm{C} 11-\mathrm{C} 12}\right) / 6$

$* * \mathrm{BLA}=R_{\mathrm{C} 12-\mathrm{C} 7}-\left[R_{\mathrm{C} 7-\mathrm{C} 8}+R_{\mathrm{C} 13-\mathrm{C} 12}\right] / 2$ 

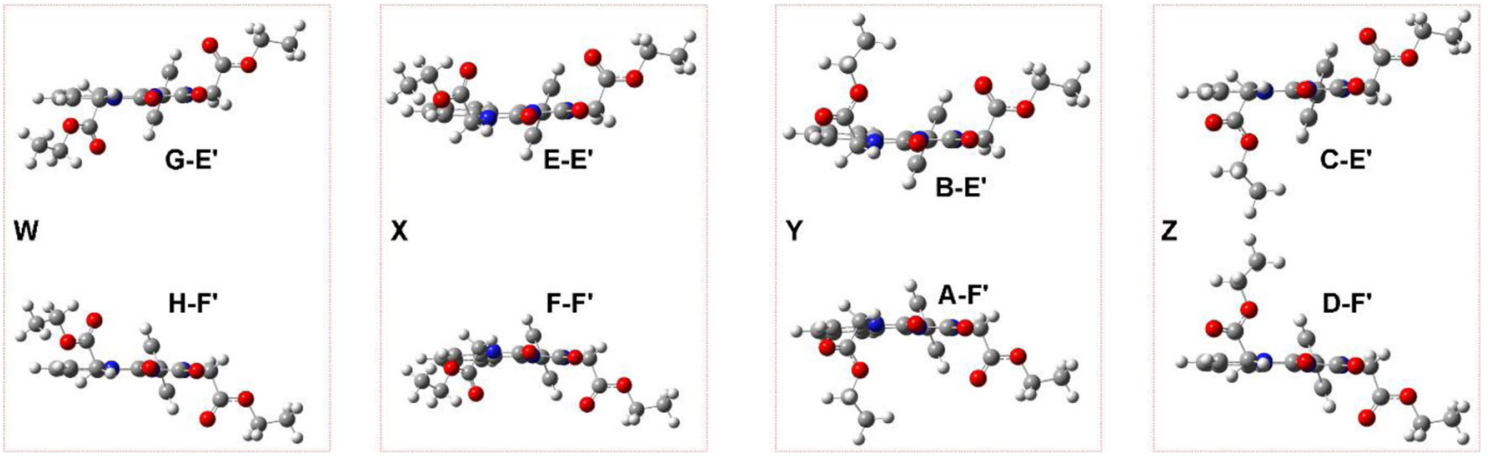

Fig. 8 Thermodynamically stable BEPIQ isomers

charges resulting from the calculations done for this dimer do not fully obey this symmetry. For example, the charge of the $\mathrm{C} 8$ atom on one molecule does not equal to the charge of the C8 atom on the second molecule, it is -0.228 vs. -0.219 , respectively.

As shown in Fig. 5, in the case of HOMO, there is one region of overlapping of the orbitals of the two enantiomers at the quinazoline ring condensation site, i.e., within the $\mathrm{C} 7-$ $\mathrm{C} 12$ bond. In turn, LUMO overlaps in two places. The overlapping of the electron cloud of the $\mathrm{C} 7-\mathrm{C} 8$ bond of one enantiomer and the $\mathrm{C} 12-\mathrm{C} 13$ bond of the other enantiomer, and the C7-C8 bond of the other with the $\mathrm{C} 12-\mathrm{C} 13$ bond of the first enantiomer, is visible.

The calculations of atomic charges for single molecules and for a pair of molecules were done. It appeared that distribution of point charges in a pair of molecules differs from the distribution in a single molecule. Especially, the differences refer to carbon atoms in the imidazoquinazolinedione ring, especially in the range of orbitals overlapping $(\mathrm{C} 1, \mathrm{C} 7, \mathrm{C} 8, \mathrm{C} 9, \mathrm{C} 10, \mathrm{C} 12$, and $\mathrm{C} 13$ ). It confirms the charge transfer between them. Additionally, the BLA parameter was calculated for the single-optimized molecule of BEPIQ and molecules within the dimer (Table 1). The charge transfer leads to a geometric distortion and the BLA parameter shows geometrical evolution of the molecular architecture. The value of BLA of the dimer is clearly reduced compared to that of a single BEPIQ molecule. The value changed from -0.02255 to $-0.02535 \AA$ and from 0.02255 to $-0.02605 \AA$ for molecule $\mathrm{GE}^{\prime}$ and $\mathrm{HF}^{\prime}$, respectively (Table 1). Even greater changes are observed in the bond area of direct overlap of molecular orbital $\left(\mathrm{C}_{8}-\mathrm{C}_{7}, \mathrm{C}_{7}-\mathrm{C}_{12}\right.$, and $\mathrm{C}_{12}-$ $\mathrm{C}_{13}$ ). They are -0.01049 and $-0.01386 \AA$ for molecule $\mathrm{GE}^{\prime}$ and -0.01048 and $-0.01656 \AA$ for molecule $\mathrm{HF}^{\prime}$ (Table 1).

Considering the values of the charges of atoms in the dimer molecules and the single molecule, it can say that upon dimer formation, atoms $\mathrm{C} 8$ and $\mathrm{C} 7$ from one molecule accept a negative charge from atoms $\mathrm{C} 12$ and $\mathrm{C} 13$ of the second molecule (and vice versa). In turn, considering the values of the charges of atoms in the lower and upper dimer molecules, the largest difference is observed for atom $\mathrm{C} 8$ and is 0.009 . Atom C8 in the upper molecule has a point charge of -0.228 and in the lower -0.219 . If we assume that this is the decisive value, the upper one molecule is the donor and the lower molecule is the acceptor in the resulting complex with the charge transfer.

The quantum-mechanical calculations described in the previous article [39] have shown that four pairs of BEPIQ enantiomers, shown in Fig. 8, are thermodynamically stable.

They can undergo mutual transformation due to the rotation of the ester substituents around the N6-C24 and C24-

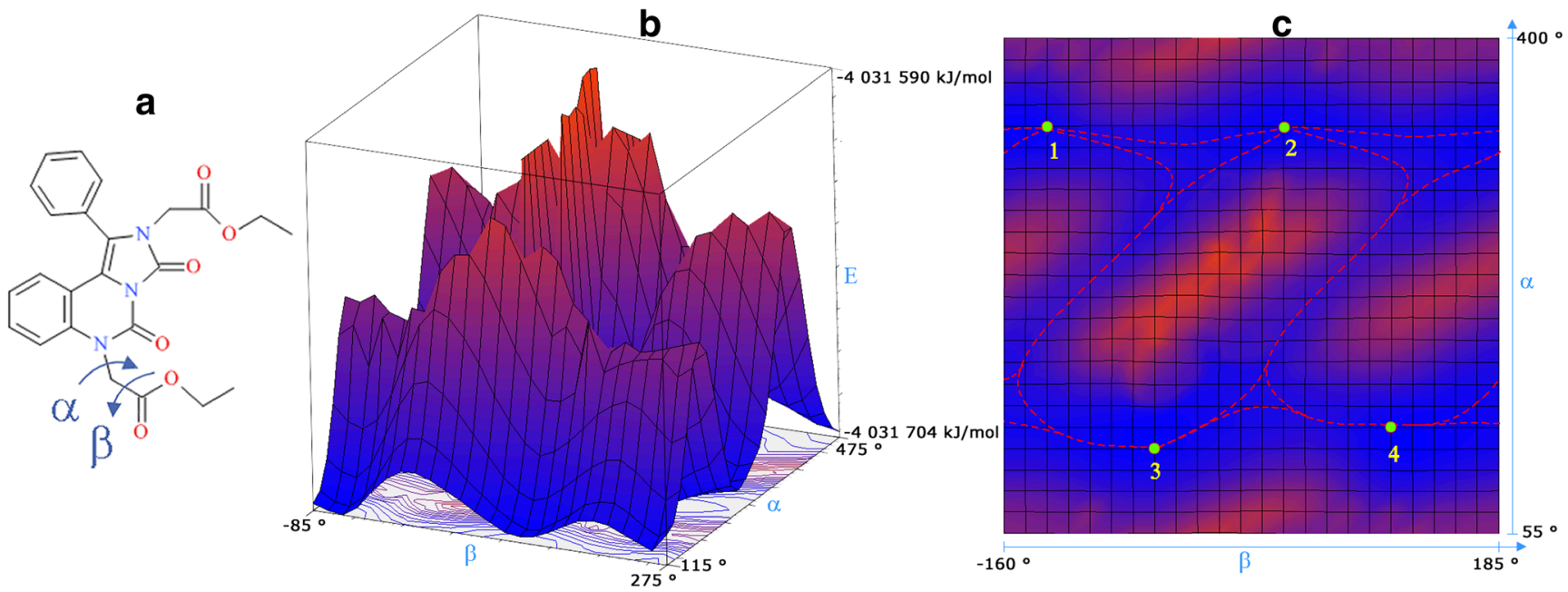

Fig. 9 The change of energy of the BEPIQ molecule (b) due to the change in angles $\alpha$ and $\beta$ of ester substituents (a); projection from above (c) 

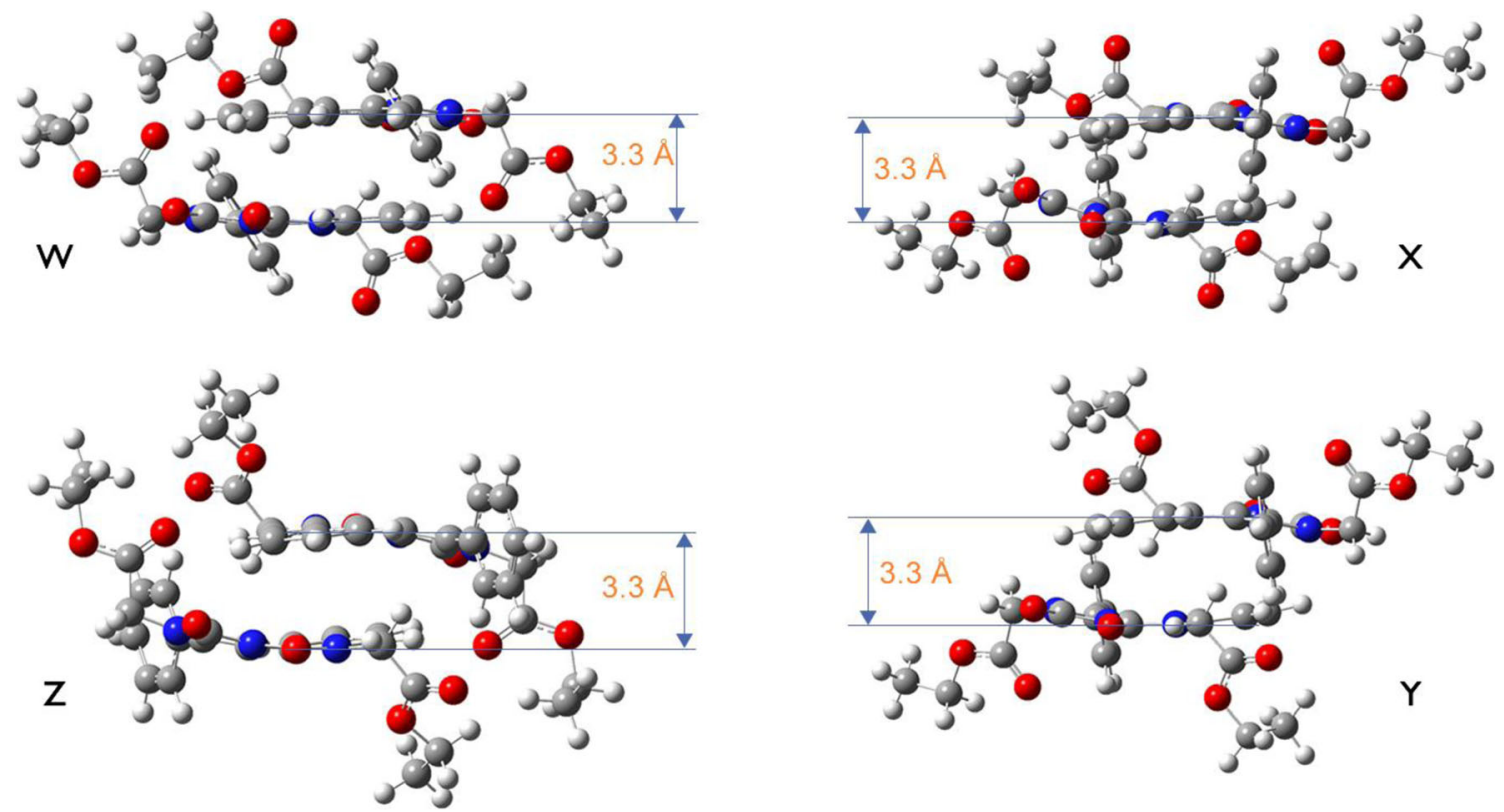

Fig. 10 Distances between the imidazoquinazoline ring planes of the enantiomeric pairs BEPIQ resulting from the structure optimization

C25 bonds, i.e., the corresponding change in angles $\alpha$ and $\beta$ are shown in Fig. 9a.

Assuming the equal angle of rotation of $15^{\circ}$ for both bonds, the energy for each determined isomer was calculated, giving a total of 576 isomers arranged in a $24 \times 24$ grid. Treating their energy (single-point energy) as a value on the $Z$-axis, the spatial visualization of potential energy surface (PES) was obtained. As is visible in Fig. 9b, the "peak" points are the highest energy isomers, while "valleys" are the most stable isomers.
By projecting from the top such a 3D scan, we get a "map" (Fig. 9c) with colors reflecting the values. The lighter the blue means the isomer has a more stable structure. Four local minimums (1, 2, 3, and 4, additionally marked with green dots) correspond to the following isomers: G-E', C-E', B-E', E-E' (shown in Fig. 8). It is worth noting that "valleys" connecting, e.g., points 1 and 3 have very low saddles, i.e., the difference in energies on the path between the G-E' and $\mathrm{B}^{-\mathrm{E}^{\prime}}$ isomers is relatively small (less than $30 \mathrm{~kJ} / \mathrm{mol}$ ) and, as shown in [39],

Table 2 Comparison of the length of the bonds, the angles between them, dihedral angles, and distances between corresponding atoms that affect electron cloud sharing, according to the atom numbering of BEPIQ shown in Fig. 6

\begin{tabular}{|c|c|c|c|c|}
\hline Signature & & Crystal measured & $\begin{array}{l}\text { Calculated in Gaussian } \\
\text { for stand-alone molecule }\end{array}$ & $\begin{array}{l}\text { Calculated in Gaussian } \\
\text { for enantiomeric molecule pair }\end{array}$ \\
\hline \multirow[t]{6}{*}{ Bond length $(\AA)$} & $\mathrm{C} 7 \mathrm{~B}-\mathrm{C} 8 \mathrm{~B}$ & $1.401(2)$ & 1.401 & 1.403 \\
\hline & $\mathrm{C} 7 \mathrm{~B}-\mathrm{C} 12 \mathrm{~B}$ & $1.409(2)$ & 1.412 & 1.417 \\
\hline & C12B-C13B & $1.445(2)$ & 1.445 & 1.447 \\
\hline & $\mathrm{C} 7 \mathrm{~A}-\mathrm{C} 8 \mathrm{~A}$ & $1.398(3)$ & 1.404 & 1.403 \\
\hline & $\mathrm{C} 7 \mathrm{~A}-\mathrm{C} 12 \mathrm{~A}$ & $1.406(2)$ & 1.415 & 1.417 \\
\hline & $\mathrm{C} 12 \mathrm{~A}-\mathrm{C} 13 \mathrm{~A}$ & $1.448(2)$ & 1.447 & 1.447 \\
\hline \multirow[t]{4}{*}{ Angle value $\left(^{\circ}\right)$} & $\mathrm{C} 8 \mathrm{~B}-\mathrm{C} 7 \mathrm{~B}-\mathrm{C} 12 \mathrm{~B}$ & $119.57(16)$ & 119.3 & 119.3 \\
\hline & $\mathrm{C} 7 \mathrm{~B}-\mathrm{C} 12 \mathrm{~B}-\mathrm{C} 13 \mathrm{~B}$ & $118.12(15)$ & 117.7 & 117.4 \\
\hline & $\mathrm{C} 8 \mathrm{~A}-\mathrm{C} 7 \mathrm{~A}-\mathrm{C} 12 \mathrm{~A}$ & $119.44(17)$ & 119.3 & 119.3 \\
\hline & $\mathrm{C} 7 \mathrm{~A}-\mathrm{C} 12 \mathrm{~A}-\mathrm{C} 13 \mathrm{~A}$ & $117.50(16)$ & 117.7 & 117.5 \\
\hline \multirow[t]{2}{*}{ Dihedral angle value $\left(^{\circ}\right)$} & $\mathrm{C} 8 \mathrm{~B}-\mathrm{C} 7 \mathrm{~B}-\mathrm{C} 12 \mathrm{~B}-\mathrm{C} 13 \mathrm{~B}$ & $179.43(16)$ & 178.8 & 179.2 \\
\hline & $\mathrm{C} 8 \mathrm{~A}-\mathrm{C} 7 \mathrm{~A}-\mathrm{C} 12 \mathrm{~A}-\mathrm{C} 13 \mathrm{~A}$ & $177.87(16)$ & 178.7 & 178.7 \\
\hline \multirow[t]{4}{*}{ Distance $(\AA)$} & $\mathrm{C} 8 \mathrm{~B}-\mathrm{C} 13 \mathrm{~A}$ & $3.407(2)$ & - & 3.308 \\
\hline & $\mathrm{C} 7 \mathrm{~B}-\mathrm{C} 12 \mathrm{~A}$ & $3.439(2)$ & - & 3.342 \\
\hline & $\mathrm{C} 12 \mathrm{~B}-\mathrm{C} 7 \mathrm{~A}$ & $3.475(2)$ & - & 3.348 \\
\hline & $\mathrm{C} 13 \mathrm{~B}-\mathrm{C} 8 \mathrm{~A}$ & $3.445(2)$ & - & 3.326 \\
\hline
\end{tabular}


Table 3 Comparison of the distances $(\AA)$ between corresponding atoms depending on the solvent

\begin{tabular}{lllll}
\hline Signature & Benzene & Chloroform & Acetone & Methanol \\
\hline C8B-C13A & 3.37773 & 3.37837 & 3.38669 & 3.43303 \\
C7B-C12A & 3.51024 & 3.43127 & 3.43142 & 3.46832 \\
C12B-C7A & 3.57286 & 3.42961 & 3.41544 & 3.44538 \\
C13B-C8A & 3.56487 & 3.36823 & 3.33278 & 3.36126 \\
\hline
\end{tabular}

enables spontaneous transformation. Even lower energy differences (ca. $10 \mathrm{~kJ} / \mathrm{mol}$ ) are in the way of G-E' transformations in $\mathrm{C}^{-\mathrm{E}^{\prime}}$ (point 1 and point 2, respectively). The transformation paths are schematically marked with a red-dotted line in Fig. 9c. Their arrangement shows that each of the four stable isomers can spontaneously transform into other ones. Observe, of course, the fact that for mirror reflections of these four isomers, there is an analogous "map" and the corresponding isomers form pairs: $\mathrm{W}, \mathrm{X}, \mathrm{Y}$, and $\mathrm{Z}$.

Since the crystal is formed by only one pair of enantiomers (W pair), the question arose whether the other three pairs of the BEPIQ enantiomers could also form complexes with charge transfer. Or is the formation of a crystal restricted to pairs of $\mathrm{W}$ enantiomers?

The distance between the planes of the imidazoquinazoline rings of the enantiomeric molecule $\mathrm{W}$ forming the crystal is about 3.5 $\AA$. Therefore, the other three pairs of enantiomers X, $\mathrm{Y}$, and $\mathrm{Z}$ were set similarly to the $\mathrm{W}$ pair. The enantiomeric molecules were positioned to each other as close as possible, i.e., to the length of the van der Waals radius of the hydrogen atoms located the closest to each other.

The distance between the planes of the imidazoquinazoline rings in the next two pairs of the enantiomers $\mathrm{X}$ and $\mathrm{Y}$ is $4.0 \AA$. It is too large for the overlapping of molecular orbits [1-3]. At the same time, the distance between the enantiomeric planes in the fourth pair of enantiomer $\mathrm{Z}$ is determined to be $3.0 \AA$.

Therefore, the process of optimizing the structures of the four pairs of enantiomers was carried out, which resulted in quite unexpected results shown in Fig. 10.
The structure of individual $\mathrm{W}$ enantiomers and their orientation in relation to each other in principle do not changeonly the distance between the planes of the imidazoquinazoline rings decreased to $3.3 \AA$.

In the case of the other three pairs of enantiomers, changes are visible both in the structure of enantiomers and in their mutual arrangement. Structural changes are primarily the deformation of the plane of the rings from the form "I " to form "( )" in which the central portions of the imidazoquinazoline rings are further apart than their outermost portions. The distance between the planes of the imidazoquinazoline rings (at the most distant positions) in all the pairs of enantiomers is about $3.3 \AA$. This would not be possible without the simultaneous changes in the mutual arrangement of the enantiomers. In Fig. 10, this is clearly seen in a pair of Y enantiomers, where the shift took place in both directions of the plane of the imidazoquinazoline rings. In addition, in the optimization process, structural changes have undergone substituents. It can be seen, for example, in the angle of inclination of the phenyl ring to the plane of the imidazoquinazoline ring in a pair of $\mathrm{X}$ enantiomers.

In contrast to the others, only a pair of $\mathrm{W}$ enantiomers is characterized by a bond arrangement shown in Fig. 6, i.e., the proper spacing of the rings from each other, the space structure arrangement of the substituents, and the nearly flat imidazoquinazoline rings.

It should be mentioned that the imidazoquinazoline rings in the pair of $\mathrm{W}$ enantiomers are not flat. As can be seen in Table 2 (with reference to Fig. 6), the angle of inclination of the six-membered planes of the rings included in the imidazoquinazoline ring is not equal to $180^{\circ}$. The difference is small $\left(\sim 1^{\circ}\right)$; however, it is observable in the crystal as well as in the results of quantum-mechanical calculations. It is worthwhile to pay attention to small differences (between those measured in the crystal and those obtained as a result of calculations) between selected enantiomeric atoms. The distances, between the atoms $\mathrm{C} 8, \mathrm{C} 7, \mathrm{C} 12$, and $\mathrm{C} 13$ of one molecule and the $\mathrm{C} 13, \mathrm{C} 12, \mathrm{C} 7$, and $\mathrm{C} 8$ of the other molecule, differ by about $0.1 \AA$ (Table 2). However, the differences in

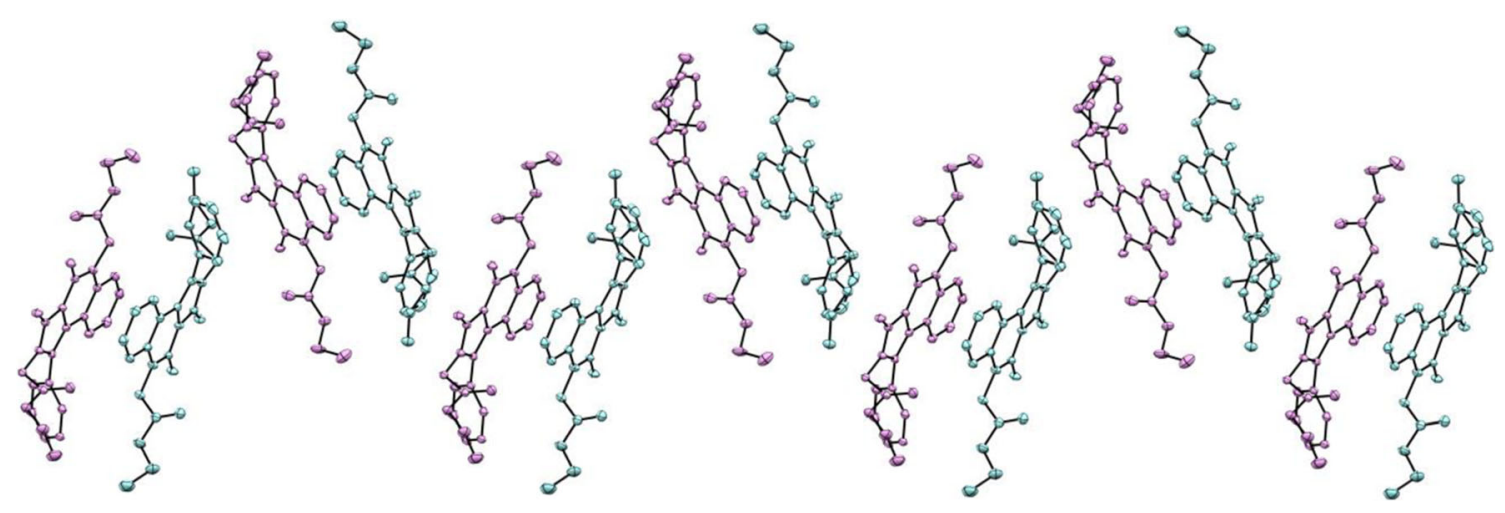

Fig. 11 Herringbone-packing scheme of the BEPIQ enantiomers 

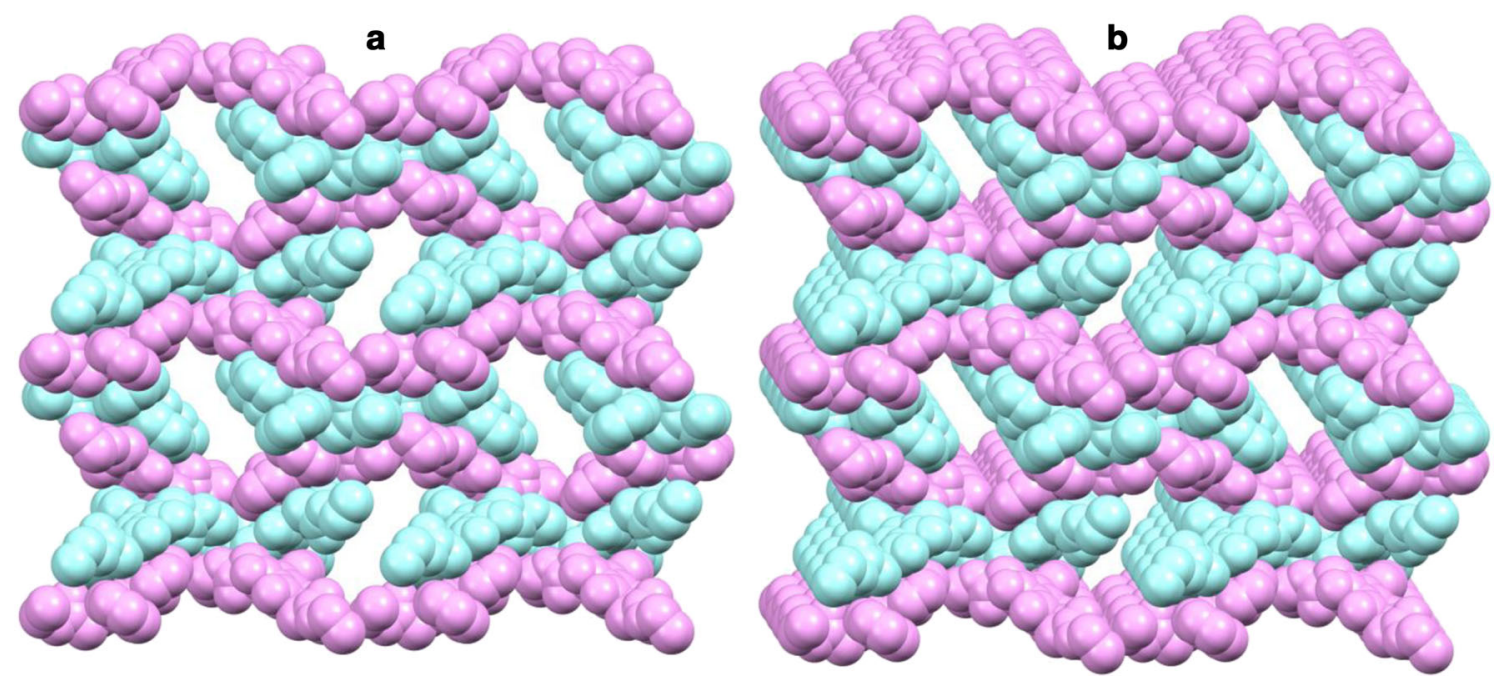

Fig. 12 Tunnels in the BEPIQ lattice. a Projection from the front. b Profile view

the length of the bonds or the angles between these atoms are several times smaller. The observed differences in bond lengths are very small whereas the ones in the angles are almost none for single-molecule $\mathrm{GE}^{\prime}$ and $\mathrm{HF}^{\prime}$ or dimer. A more noticeable difference concerns the values of dihedral angles (Table 2).

The location of the ester substituents relative to the plane of the imidazoquinazoline ring is also important in the point of view of spatial packing. In the case of the enantiomeric pairs of $\mathrm{W}$ and $\mathrm{Z}$, the ester substituents are arranged in the trans configuration. However, both substituents, in the pair of W enantiomers, are in a parallel position to the imidazoquinazoline ring, and in the pair of $Z$ enantiomers, one of the substituents assumes a parallel position and the other is perpendicular. The parallel arrangement of both substituents provides a higher packing density of the BEPIQ molecules in the crystal lattice. A spatial discharging takes place, as in the case of disubstituted cyclohexane derivatives with the preferential equatorial position of substituents [41].

The influence of environmental polarization was also considered. The following solvents benzene, chloroform, acetone, and methanol were taken into account. The structure optimization of the dimer shows that the largest distances between the suitable atoms (first column at Table 3) are in non-polar benzene. This may be due to the fact that the imidazoquinazoline ring planes are a little bit shifted to each other. The smallest distances were obtained for chloroform and acetone, but a slight shift of planes was visible. Notwithstanding, the minimal plane shift occurs for non-solvent optimization what best suited the crystal.

When considering the structure of the BEPIQ crystal lattice, it was noticed that the $\mathrm{W}$ enantiomeric pairs are arranged at an angle of about $67^{\circ}$ to each other and form the so-called herringbone. The characteristic way of the BEPIQ packing in the crystal is shown in Fig. 11.
It is noted that there are gaps in the given BEPIQ lattice layer, which consequently form regular, open tunnels, as shown in Fig. 12.

It should also be noted that in the BEPIQ crystal lattice tunnels, there are benzene molecules, which were the solvent used for crystallization. The presence of benzene molecules is shown in Fig. 13. It follows that BEPIQ has the ability to form inclusion compounds [42].

Considering in turn the arrangement of the BHEPIQ molecules in the crystal (Figs. 3 and 14), it was noticed that there

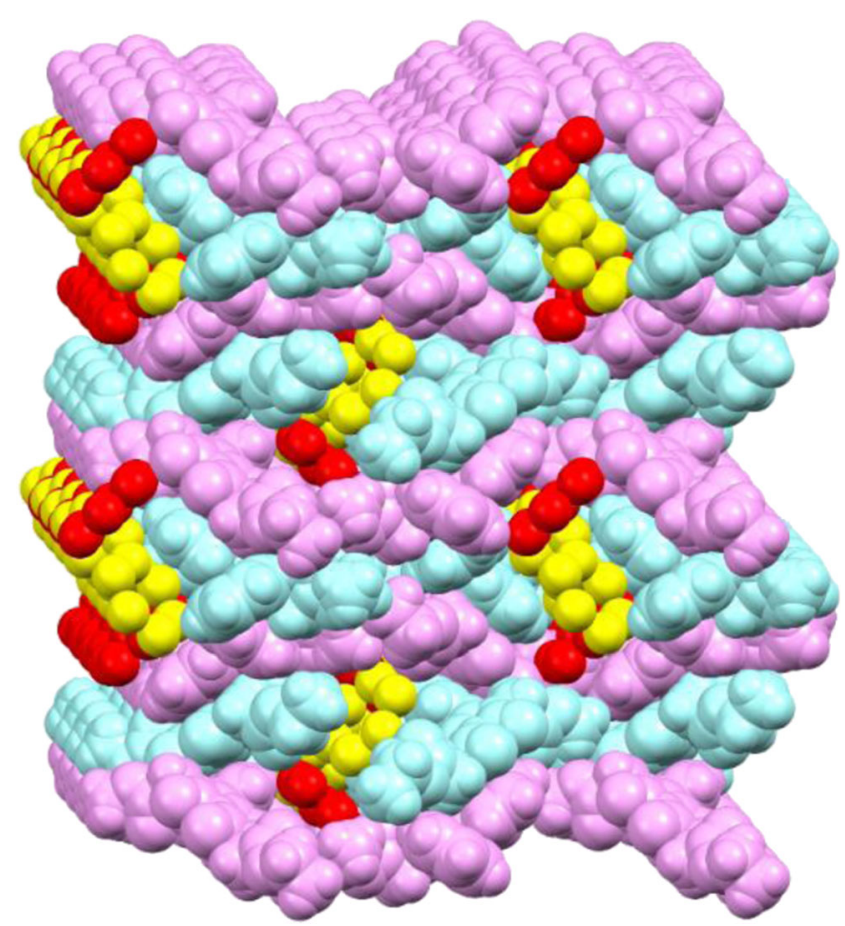

Fig. 13 BEPIQ and benzene inclusion compound; benzene molecules are marked with red and yellow 


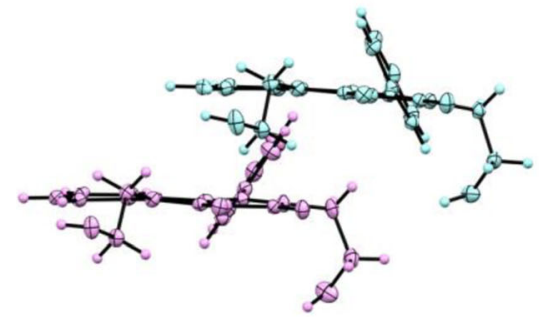

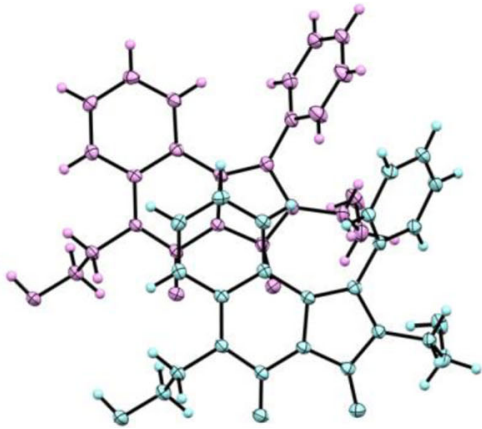

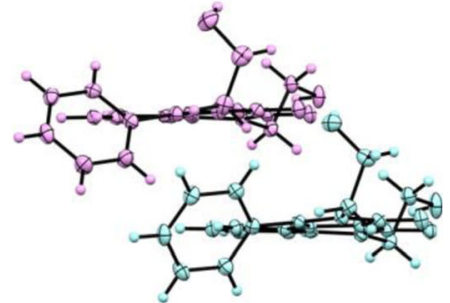

Fig. 14 An arrangement the BHEPIQ molecules with respect to each other in the crystals

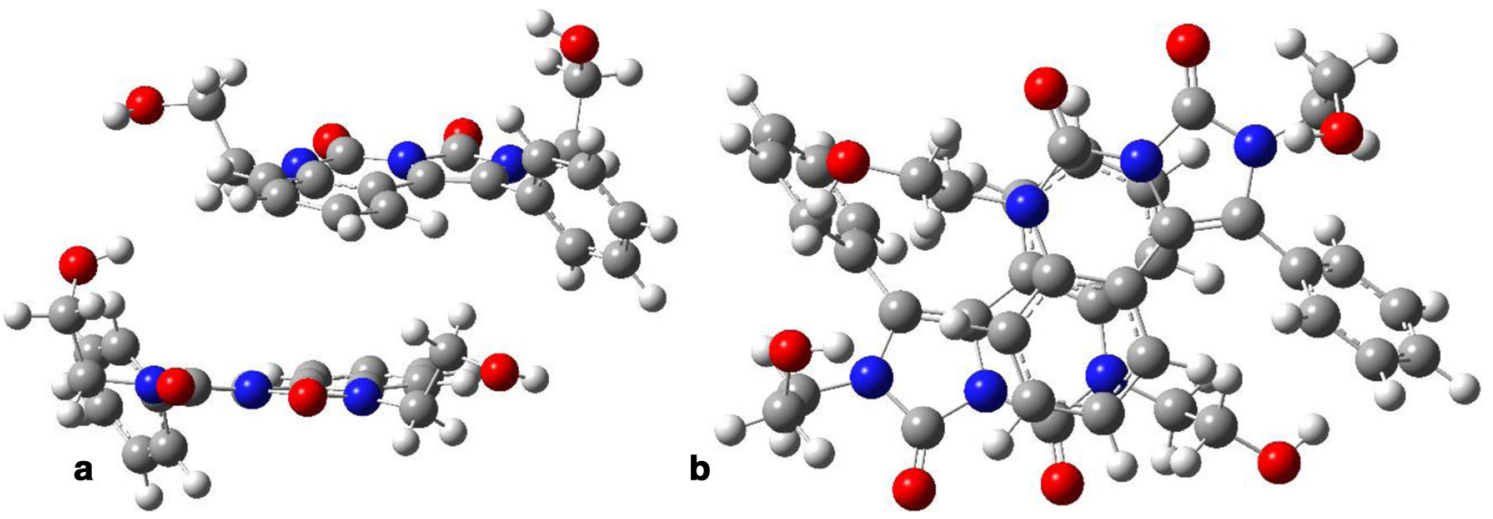

Fig. 15 Optimized arrangement of the BHEPIQ molecule pair. a Side view. b Projection from the top

are two different molecules present. They differ mainly by torsion angle between phenyl substituent and central fused rings. It was described in detail in [40].

The imidazoquinazoline rings of individual pairs of molecules are arranged parallel to each other. However, this is not the centrosymmetric arrangement as in the case of the BEPIQ enantiomers. In addition, one of the hydroxyethyl substituents assumes a parallel position and the other one is perpendicular

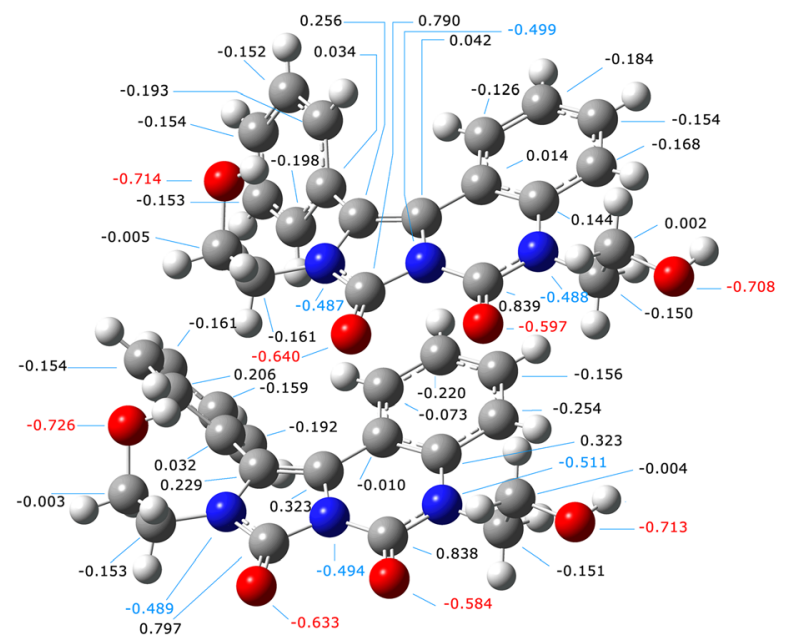

to the plane of the imidazoquinazoline ring. The molecules are arranged in the "head to head" position.

Quantum-mechanical modeling confirmed that with this non-centrosymmetric arrangement of the BHEPIQ molecules, overlapping of their HOMO and LUMO is not possible. Therefore, the BHEPIQ molecules were arranged for calculation in relation to each other following the model of the BEPIQ molecules.

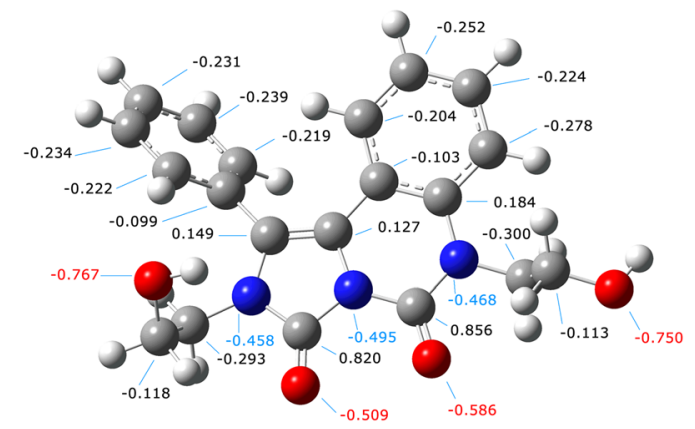

Fig. 16 Atomic point charges of the BHEPIQ molecule calculated by the NBO method calculated for a pair of enantiomeric molecules and for single molecule. Point charges of hydrogen atoms were omitted for clarity 


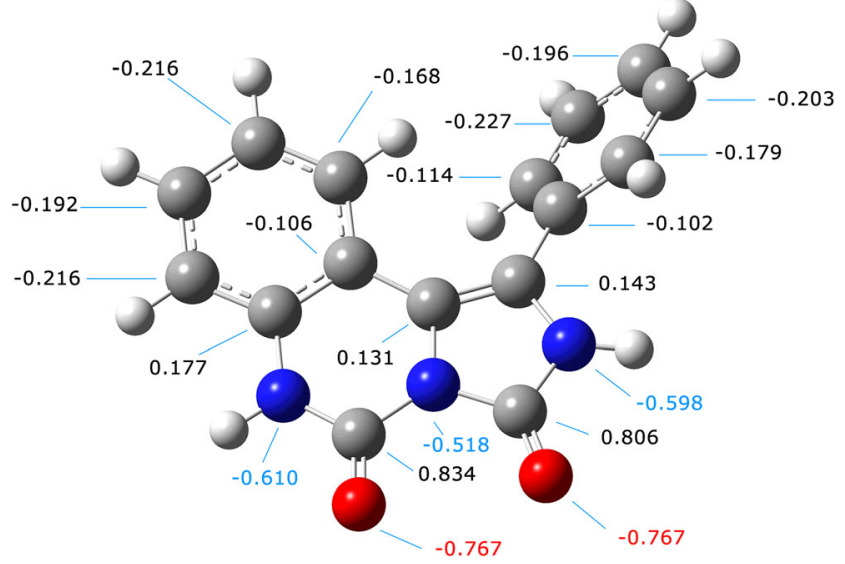

Fig. 17 The atomic point charge in the PIQ molecule

However, also in this case, the modeling did not show the formation of charge-transfer complexes. Therefore, the mutual placement of the BHEPIQ molecules was optimized and the optimization results are visualized in Fig. 15.

This energetically optimal arrangement of the BHEPIQ molecules is not centrosymmetric, and it does not lead to the overlapping of their HOMO and LUMO during the quantummechanical modeling. Nevertheless, it should be noted that the potential dimer may not represent global energy minimum.

It investigated the charge distribution in the BHEPIQ and it is shown in Fig. 15. Distribution of the atom charges in a single molecule of BHEPIQ is analogous to the charge distribution of PIQ. Interaction of the BHEPIQ molecules causes the atom charges in both molecules to be different and they differ from a single molecule.

The charge distribution in the BHEPIQ imidazoquinazoline ring is different to that of the BEPIQ molecule (comparing Fig. 7 and Fig. 16). The key difference relates to atom no. 12, on which the charge located in the BHEPIQ molecule in the suggested dimer is -0.010 or 0.014 , while BEPIQ shows a more negative charge on it $(-0.103$ or 0.101$)$. Also, attention is paid to the charge of atom no. 13 BHEPIQ ( 0.323 or 0.042$)$ in comparison to BEPIQ ( 0.140 or 0.139$)$.

It was verified that the charge distribution of the BEPIQ molecule forming a complex with charge transfer is analogous to the distribution of PIQ charges. Charges differ little in values and they retain their characters, which can be seen by comparing Fig. 7 and Fig. 17, e.g., carbon atom no. $9(-0.192$ and -0.191$)$, carbon atom no. $11(-0.168$ and -0.169$)$, carbon atom no. 13 ( 0.131 and 0.126$)$, and carbon atom no. 14 (0.102 and -0101$)$.

Considering the influence of substituents on the charge distribution in the imidazoquinazoline ring, it should be noted that hydroxyethyl substituents have stronger electron donor than ester substituents. Therefore, the electron density of the BHEPIQ imidazoquinazoline ring is higher and less diversified in comparison to the BEPIQ or PIQ molecule. Carbon atom nos. $8,9,10$, and 11 in BHEPIQ have point charges lower than -0.2 , i.e., $-0.278,-0.224,-0.252$, and -0.204 , respectively. Whereas, the same atoms in PIQ and BEPIQ have lower charges, $-0.216(-0.200) ;-0.192(-0.191)$; $0.216(-0.228)$; and $-0.168(-0.169)$, respectively.

A different distribution of charge in the BHEPIQ quinazoline ring and non-centrosymmetric arrangement of the molecule pair explain the lack of formation of complexes with charge transfer.

For the spatial arrangement of the BHEPIQ molecules in the crystal lattice, hydrogen bonds formed with the participation of hydroxyl groups are responsible. Molecular interactions arising from the formation of intermolecular hydrogen bonds are stronger than intermolecular interactions arising as a result of creating complexes with charge transfer [1-3]. Therefore, the hydrogen bonds are a decisive factor in the arrangement of molecules in the crystal.

In turn, the structure of the BEPIQ molecules does not allow for the formation of the hydrogen bonds. The effect of the presence of the hydrogen bonds on the BHEPIQ spatial structure is described in detail in [40].

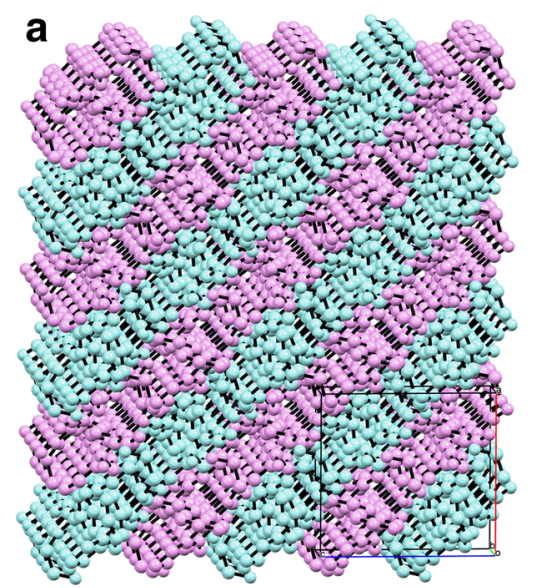

b

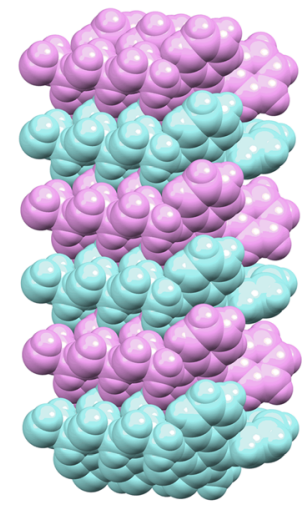

C

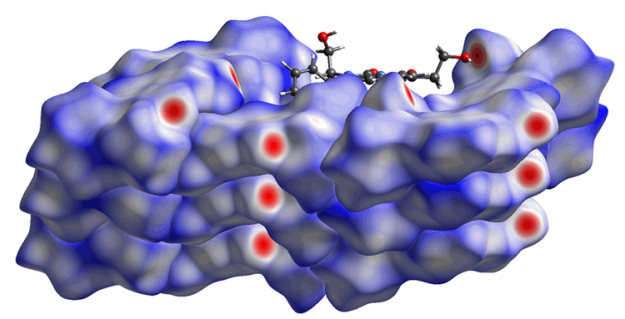

Fig. 18 Column stackings of BHEPIQ. a The lattice fragment. b Single stack. c Stack with respect of a Hirshfeld surface 
Finally, in the crystal, the BHEPIQ molecules are packed into column stackings, as shown in Fig. 18. The stacking's formation is further confirmed by the Hirshfeld surface depicted in Fig. 18c.

\section{Summary of results}

The crystallographic structure of 2,6-bis(ethoxycarbonylmethyl)1-phenylimidazo[1,5-c]quinazoline-3,5-dione, i.e., the isomer's arrangement to each other and in the crystal, results from the overlapping of the molecular orbitals of the imidazoquinazoline rings of couple enantiomers, i.e., formation of complexes with charge transfer. Both the donor and the acceptor are the enantiomers of the BEPIQ diester and considering the distribution of charges in the overlap of molecular orbitals, it is virtually impossible to indicate which of the enantiomers is the donor and which the acceptor.

It has been calculated that the formation of charge-transfer complexes between the BEPIQ molecules is possible only between the two enantiomers building the crystal. The formation of the crystal by the selected pair of enantiomers is determined by the spatial structure of the single enantiomer, and precisely, the parallel arrangement of the imidazoquinazoline rings and the position of the substituents relative to the imidazoquinazoline ring, allowing a higher packing density of the molecules.

The BEPIQ enantiomeric molecules are aligned with each other in the "head to tail" position. In turn, the pairs of enantiomers are aligned with each other from an angle of about $68^{\circ}$ to form a characteristic herringbone.

In the BEPIQ crystal lattice, tunnels are formed in which the molecules of benzene - the solvent used for crystallizationhave been sealed. In this way, new inclusion compounds were obtained.

The arrangement of the 2,6-bis(2-hydroxyethyl)-1phenylimidazo[1,5-c]quinazoline-3,5-dione molecules in the crystal results from the structural possibilities of the formation of intermolecular hydrogen bonds. The BHEPIQ molecules do not form complexes with charge transfer, and the reason is a different distribution of charges in the imidazoquinazoline ring and non-centrosymmetric arrangement compared to BEPIQ. The BHEPIQ molecules forming the intermolecular hydrogen bonds show stronger interactions compared to the BEPIQ molecules.

The BHEPIQ molecules assume a "head to head" position and are arranged in parallel to each other in the crystal lattice forming the stackings.

Acknowledgements The authors would like to thank the Interdisciplinary Centre for Mathematical and Computational Modelling in Warsaw for providing computer facilities for the possibility of performing the quantum-mechanical calculations under grant G49-12.

\section{Compliance with ethical standards}

Conflict of interest The authors declare that they have no conflicts of interest.

Open Access This article is distributed under the terms of the Creative Commons Attribution 4.0 International License (http:// creativecommons.org/licenses/by/4.0/), which permits unrestricted use, distribution, and reproduction in any medium, provided you give appropriate credit to the original author(s) and the source, provide a link to the Creative Commons license, and indicate if changes were made.

\section{References}

1. Pyykkö P, Atsumi M (2009) Molecular single-bond covalent radii for elements 1-118. Chem Eur J 15(1):186-1978

2. Pyykkö P, Atsumi M (2009) Molecular double-bond covalent radii for elements Li-E112. Chem Eur J 15(46):12770-12779

3. Pyykkö P, Riedel S, Patzschke M (2005) Triple-bond covalent radii. Chem Eur J 11(12):3511-3520

4. Pigoń K, Ruziewicz Z (2005) Chemia Fizyczna. Polskie Wydawnictwo Naukowe PWN, Warszawa

5. Desiraju G (2002) Hydrogen bridges in crystal engineering: interactions without borders. Acc Chem Res 35:565-573

6. Arunan E, Desiraju GR, Klein RA, Sadlej J, Scheiner S, Alkorta I, Clary DC, Crabtree RH, Dannenberg JJ, Hobza P, Kjaergaard HG, Legon AC, Mennucci B, Nesbitt DJ (2011) Definition of the hydrogen bond (IUPAC Recommendations 2011). Pure Appl Chem 83(8):1637-1641

7. Steiner T (2002) The hydrogen bond in the solid state. Angew Chem Int Ed 41(1):48-76

8. Hunter CA, Sanders JKM (1990) The nature of $\pi-\pi$ interactions. J Am Chem Soc 14:5525-5534

9. Robertazzi A, Krull F, Knapp EW, Gamez P (2011) Recent advances in anion- $\pi$ interactions. Cryst Eng Comm 13:3293-3300

10. Chifotides HT, Dunbar KR (2013) Anion $-\pi$ interactions in supramolecular architectures. Acc Chem Res 46:894-906

11. Gamez P (2014) The anion- $\pi$ interaction: naissance and establishment of a peculiar supramolecular bond. Inorg Chem Front 1:35-43

12. Foster R (1980) Electron donor-acceptor complexes. J Phys Chem $84: 2135-2141$

13. Orozco-Valencia U, Gazquez JL, Vela A (2018) Global and local charge transfer in electron donor-acceptor complexes. J Mol Model 24(9):250-258

14. Marciniak B, Rozycka-Sokolowska E (2009) 4-Methoxy-1-naphthol: chains formed by $\mathrm{O}-\mathrm{H} \cdot \cdots \mathrm{O}$ hydrogen bonds and $\pi \bullet \bullet \pi$ stacking interactions. Acta Crystallographica C 65:0630-o634

15. Kim YH, Jeong HC, Kim SH, Yang K, Kown SK (2005) Highpurity-blue and high-efficiency electroluminescent devices based on anthracene. Adv Funct Mater 15(11):1799-1805

16. Zheng CJ, Zhao WM, Wang ZQ, Huang D, Ye J, Ou XM, Zhang XH, Lee CS, Lee ST (2010) Highly efficient non-doped deep-blue organic light-emitting diodes based on anthracene derivatives. J Mater Chem 20:1560-1566

17. Marrocchi A, Silvestri A, Seri M, Facchetti A, Taticchi A, Marks TJ (2009) Conjugated anthracene derivatives as donor materials for bulk-heterojunction solar cells: olefinic versus acetylenic spacers. Chem.Commun. 0:1380-1382 
18. Park JH, Chung DS, Lee DH, Kong H, Jung IH, Park MJ, Cho NS, Park CE, Shim HK (2010) New anthracene-thiophene-based copolymers that absorb across the entire UV-vis spectrum for application in organic solar cells. Chem Commun 46(11):1863-1865

19. Anthony JE, Eaton DL, Parkin SR (2002) A road map to stable, soluble, easily crystallized pentacene derivatives. Org Lett 4(1):1518

20. Li XC, Sininghaus H, Garnier F, Holmes AB, Moratti SC, Feeder N, Clegg W, Teat SJ, Friend RH (1998) A highly $\pi$-stacked organic semiconductor for thin film transistors based on fused thiophenes. J Am Chem Soc 120(9):2206-2207

21. Eyehmuller A, Rogach AL (2000) Chemistry and photophysics of thiol-stabilized II-VI semiconductor nanocrystals. Pure Appl Chem 72:179-188

22. Baj H, Wang Y, Cheng P, Li Y, Zhu D, Zhan X (2014) Acceptordonor-acceptor small molecules based on indacenodithiophene for efficient organic solar cells. ACS Appl Mater Interfaces 6(11): 8426-8433

23. Adam AMA, Refat MS (2016) Solution and solid-state investigations of charge transfer complexes caused by the interaction of bathophenanthroline with different organic acceptors in a (methanol+dichloromethane) binary solvent system. J Mol Liq 219:377389

24. Yakuphanoglu F, Arslan M (2004) The fundamental absorption edge and optical constants of charge transfer compounds. Opt Mater 27:29-39

25. Refat MS, Sharshar T, Elsabawy KM, El-Sayed MY, Adam AMA (2016) Synthesis, physicochemical characterization and anticancer screening of sulfa drug ruthenium complexes as anticancer agent. $\mathrm{J}$ Mol Liq 222:334-349

26. Mulliken RS (1952) Molecular compounds and their spectra. 2. J Am Chem Soc 74:811-824

27. Sennikov PG, Egorochkin AN (1982) Electronic spectroscopy of complexes with a charge-transfer as a method of studying intramolecular interactions in organic and hetero-organic compounds. Usp Khim 51:561-585

28. Kochi JK (1991) Charge-transfer excitation of molecularcomplexes in organic and organometallic chemistry. Pure Appl Chem 63:255-264

29. Eyehmuller A, Rogach AL (2000) Chemistry and photophysics of thiol-stabilized II-VI semiconductor nanocrystals. Pure Appl Chem 72:179-188

30. Gaballa AS, Amin AS (2015) Preparation, spectroscopic and antibacterial studies on charge-transfer complexes of 2hydroxypyridine with picric acid and 7,7',8,8'-tetracyano-pquinodimethane. Spectrochim Acta A 145:302-312

31. Frisch MJ, Trucks GW, Schlegel HB, Scuseria GE, Robb MA, Cheeseman JR, Scalmani G, Barone V, Petersson GA, Nakatsuji
H, Li X, Caricato M, Marenich A, Bloino J, Janesko BG, Gomperts R, Mennucci B, Hratchian HP, Ortiz JV, Izmaylov AF, Sonnenberg JL, Williams-Young D, Ding F, Lipparini F, Egidi F, Goings J, Peng B, Petrone A, Henderson T, Ranasinghe D, Zakrzewski VG, Gao J, Rega N, Zheng G, Liang W, Hada M, Ehara M, Toyota K, Fukuda R, Hasegawa J, Ishida M, Nakajima T, Honda Y, Kitao O, Nakai H, Vreven T, Throssell K, Montgomery Jr JA, Peralta JE, Ogliaro F, Bearpark M, Heyd JJ, Brothers E, Kudin KN, Staroverov VN, Keith T, Kobayashi R, Normand J, Raghavachari K, Rendell A, Burant JC, Iyengar SS, Tomasi J, Cossi M, Millam JM, Klene M, Adamo C, Cammi R, Ochterski JW, Martin RL, Morokuma K, Farkas O, Foresman JB, Fox DJ (2016) Gaussian 09, Revision A.02. Gaussian, Inc., Wallingford

32. Parr RG, Yang W (1989) Density-functional theory of atoms and molecules. Oxford Univ. Press, Oxford

33. Becke AD (1993) Density-functional thermochemistry. III. The role of exact exchange. J Chem Phys 98:5648-5652

34. Carey FA, Sundberg RJ (2007) Advanced organic chemistry structure and mechanisms5th edn. Springer Science + Business Media, Berlin

35. Reed AE, Curtiss LA, Weinhold F (1988) Intermolecular interactions from a natural bond orbital, donor-acceptor viewpoint. Chem Rev 88:899-926

36. Dennington R, Keith T, Millam J (2009) Gauss view, version 5. Semichem Inc., Shawnee Mission

37. Macrae CF, Bruno IJ, Chisholm JA, Edgington PR, McCabe P, Pidcock E, Rodriguez-Monge L, Taylor R, van de Streek J, Wood PA (2008) Mercury CSD 2.0-new features for the visualization and investigation of crystal structures. J Appl Crystallogr 41:466-470

38. Turner MJ, McKinnon JJ, Wolff SK, Grimwood DJ, Spackman PR, Jayatilaka D, Spackman MA (2017) CrystalExplorer17 University of Western Australia

39. Hęclik K, Szyszkowska A, Trzybiński D, Woźniak K, Klasek A, Zarzyka I (2017) Esters with imidazo[1,5-c] quinazoline ring - spectral characterization and quantum-mechanical modeling. J Mol Model 23(107):1-12

40. Szyszkowska A, Trzybiński D, Pawlędzio S, Woźniak K, Klasek A, Zarzyka I (2018) New diols with imidazo[1,5-c]quinazoline-3,5dione ring. J Mol Struct 1153:230-238

41. Leventis N, Hanna SB, Sotiriou-Leventis C (1997) A threedimensional energy surface for the conformational inversion of cyclohexane. J Chem Educ 74:813-814

42. George AR, Harris KDM (1995) Representing and understanding geometric features of one-dimensional tunnel structures in solid inclusion compounds. J Mol Graph 13:138-141

Publisher's note Springer Nature remains neutral with regard to jurisdictional claims in published maps and institutional affiliations. 